\title{
Criterion Validity of the Physical Activity Scale (PAS2) in Danish Adults
}

\author{
ESL Pedersen $^{1,2}$, LH Mortensen ${ }^{3,4}$, S Brage $^{5}$, AL Bjerregaard $^{6}$, and M Aadahl ${ }^{2,7}$ \\ ${ }^{1}$ Institute of Social and Preventive Medicine, University of Bern, Bern, Switzerland ${ }^{2}$ Research \\ Centre for Prevention and Health, Rigshospitalet - Glostrup, Ndr. Ringvej 57, Building 84/85, \\ 2600 Glostrup, Denmark ${ }^{3}$ Section of Social Medicine, University of Copenhagen, Copenhagen, \\ Denmark ${ }^{4}$ Methods and Analysis, Statistics Denmark, Copenhagen, Denmark ${ }^{5} \mathrm{MRC}$ \\ Epidemiology Unit, University of Cambridge, Cambridge, United Kingdom ${ }^{6}$ Section of General \\ Practice, Department of Public Health, Aarhus University, Aarhus, Denmark ${ }^{7}$ Department of \\ Public Health, Faculty of Health and Medical Sciences, University of Copenhagen, Copenhagen, \\ Denmark
}

\section{Abstract}

Background-The Physical Activity Scale (PAS2) was developed to measure physical activity during work, transportation, and leisure time, in the Danish adult population. The objective of this study was to assess the criterion validity of PAS2 against a combined accelerometer and heart rate monitor in Danish adults and to investigate if the criterion validity differed by sociodemographic factors and body mass index.

Method-A total of 330 Danish adults (mean age $=46.7$ years, $38.5 \%$ men) participating in the Health2008 study completed the PAS2 questionnaire and wore a combined accelerometer and heart rate sensor for seven days. Average daily estimates from PAS2 was categorised into time spent in sedentary behaviour, light physical activity, moderate physical activity, and vigorous physical activity and compared to the objective measures.

Results-PAS2 accounted for 19.5 hours/day on average. Time spent in sedentary behaviour, light, and moderate intensity PA was weakly correlated with objective data (correlation coefficient (PCC): $0.18-0.20$ ), whereas vigorous intensity physical activity was moderately correlated (PCC: $0.54, \mathrm{p}=0.04)$. Mean bias was -2.3 hours/day ( $95 \%$ limits of agreement $(\operatorname{LoA})$ : -9.04 to 4.34 ) for sedentary behaviour, 1.68 hours/day (LoA: 8.02 to -4.62) for light activity, 0.55 hours/day (LoA: 3.37 to -2.26 ) for moderate activity and 0.12 hours/day (LoA: 0.57 to 0.33 ) for vigorous activity. Criterion validity was lower in women, in participants who were above 40 years, overweight, had short education and were unemployed.

Corresponding author: Eva Sophie Lunde Pedersen, Institute of Social and Preventive Medicine, University of Bern, Finkenhubelweg 11,3012 Bern, Switzerland, eva.pedersen@ispm.unibe.ch.

Competing interest

The authors declare that there is no conflict of interest 
Conclusion-PAS2 overestimated time spent on light, moderate, and vigorous intensity physical activity and underestimated time spent sedentary behaviour. Validity differed by key sociodemographic characteristics.

\section{Keywords}

Sedentary lifestyle; Physical activity; Activities of daily living; Objective measure; Questionnaire; Validation; Criterion validity

\section{Introduction}

There is strong evidence that physical inactivity increases the risk of adverse health outcomes and shortens life expectancy $(1,2)$, whereas regular moderate-to-vigorous physical activity (MVPA) can effectively reduce the risk of mortality and chronic disease. In addition, an increasing number of observational studies have found deleterious health effects of prolonged sedentary behaviour (3). Valid and feasible instruments for measuring sedentary behaviour and physical activity at population level are necessary for continued research into the associated health effects and for monitoring recommended levels and temporal changes in physical activity and sedentary behaviour. Although objective methods are becoming increasingly available and affordable even for use in large study populations, self-report questionnaires are still needed to provide information on physical activity and sedentary behaviours in different domains, e.g. at work, during leisure time and transportation (4).

The Physical Activity Scale (PAS2) was developed to estimate physical activity and sedentary behaviour in the adult Danish population (5). The questionnaire consists of seven items measuring duration of sleep, sedentary behaviour and physical activity of different intensities at work, during transportation, and leisure time. Other validated questionnaires for measuring physical activity already exist; among those is the frequently used international physical activity questionnaire (IPAQ). Criterion validity studies of the IPAQ show poor to moderate agreement between self-report and objective measurements (correlation coefficients between $r=0.15$ and $r=0.49$ ) and a tendency for the IPAQ to overestimate time spent in MVPA and underestimate time spent in sedentary behaviour compared to objective measures (6-10). In two of these studies, they also showed that IPAQ measures physical activity and sedentary behaviour differently depending on sex, age and job status $(6,11)$. PAS2 is a one-page self-report questionnaire and it is a modification of The Physical Activity Scale (PAS) that was developed and validated against diary and uniaxial accelerometry collected at hip level in 2003 (12) and against VO2max in 2007 (13). PAS2 was validated in terms of face and construct validity using cognitive interviewing (5) but PAS2 has not yet been validated against an objective criterion measure. Therefore, the aim of this study was to assess the criterion validity of PAS2 against combined accelerometry and heart rate monitoring in 330 Danish adults who participated in the Danish health examination 'Health2008'. A secondary aim was to investigate if the criterion validity of PAS2 differed by age, gender, body mass index (BMI), educational level, or employment status. 


\section{Methods}

\section{Study Population}

A random sample of 2218 men and women between 30 and 60 years of age living in the Western part of the Copenhagen area was extracted from the Danish Civil Registration System and invited to participate in the Health2008 study, a substudy of the Health2006 (14). The purpose of Health2008 was to study and validate tests and questionnaires used in Health2006. In the invitation letter it was specified that pregnant women, persons unable to perform physical activities such as bicycling and climbing stairs, and persons with known cardiovascular disease, diabetes, chronic obstructive pulmonary disease, hypertension or history of blood clots were not eligible. A total of 795 eligible persons accepted the invitation (36\% of the initially invited population). All participants ( $n=795)$ were asked to wear a combined accelerometry and heart rate monitor for 7 days. Of these, 463 accepted (58\% of the 795 participants). Participants were excluded if the monitor was defect $(n=45)$, if the quality of the measurements were inadequate $(n=66)$ or if the total wear time of the monitor was less than 24 hours $(n=22)$.

The Ethics Committee of the Copenhagen Region approved the collection and of data for the Health2008 study (H-KA20060011) and all participants provided written informed consent.

\section{Procedure}

Participants received a self-report questionnaire by post (of which PAS2 was a part), which they filled in before arriving for the health examination at the Research Centre. The health examination lasted five hours and included testing of cognitive, psychological and physical functions. At the examination, participants were asked if they were willing to wear an activity monitor for the following seven days. If participants agreed, the monitor was positioned on their chest and the monitor was returned by mail after seven days.

\section{Self-Reported PA}

PAS2 is a one-page self-administered questionnaire for estimating respondents' time spent in different types of physical activity and different activity levels. PAS2 comprises 9 items of which 4 items ask about time spent on different daily activities and 3 items ask about time spent on weekly activities. On a daily basis, the questionnaire asks about duration of sleep, sedentary behaviour and physical activity during leisure time, at work and while commuting to and from work. On a weekly basis, the questionnaire asks about light, moderate and vigorous physical activity during leisure time. In Table 1 an overview of the questions in PAS2 is presented and in table E1 contains a copy of the questionnaire.

Each question in PAS2 represents a specific level of MET intensity based on The Compendium of Physical Activity (15): sleep = 0.9 MET, TV viewing/reading = 1.0 METs, sitting work $=1.5 \mathrm{METs}$, standing/walking work $=2.0 \mathrm{METs}$, light leisure time physical activity $=3.0$ METs, active transportation $=4.0$ METs, heavy work $=5.0$ METs, moderate leisure time physical activity $=5.0 \mathrm{METs}$, vigorous leisure time physical activity $=6.0$ METs. Sleep, TV time, and sitting at work were categorized as sedentary behaviour. Standing/walking at work and light leisure time physical activity were categorized as light 
activity. Heavy work, active transportation and moderate leisure time physical activity were categorized as Moderate activity, and vigorous leisure time physical activity was categorized as vigorous activity (Table 1).

To estimate average time spent per day, weekly leisure time physical activity of light, moderate and vigorous intensity (question 5-7) was divided by seven. Total reported time per day was calculated by adding all hours from all questions in PAS2. Where total time was below 24 hours, we added time that was not accounted for to the category light physical activity, and where time total was above 24 hours, the surplus hours were subtracted from light physical activity. This approach was based on previous findings indicating that the duration of light intensity activities, e.g. light cleaning or standing at home (1.5-2-5 METs) are very difficult for most respondents to assess and are therefore the most variable activities (12).

\section{Combined Heart rate and Accelerometer Monitoring}

The objective measures of physical activity and sedentary behaviour were obtained by a combined accelerometer and heart rate monitor (Acc+ HR), (Actiheart, CamNtech Ltd., Cambridge, UK) (16) set up to record information about acceleration and heart rate every 60 seconds. Combined heart rate and accelerometer measurement is considered superior to accelerometer measurement alone, as heart rate provides additional information for determination of the intensity of performed activities (17). When combining accelerometer and heart rate data by branched equation modelling, the accelerometer data are predominantly used during low levels of heart rate and movement whereas heart rate information is predominantly used when both heart rate and acceleration levels are high. The monitor was attached to participants' chest with two standard electrocardiogram electrodes ( $3 \mathrm{M}^{\mathrm{TM}}$,Minnesota, US), one at the lower part of the sternum and the other one placed to the left as laterally as possible on the same horizontal level (18). Participants wore the monitor for seven consecutive days and were asked only to take it off when engaging in water activities other than showering. Calibration of the heart rate signal to energy expenditure was based on a gender-stratified group calibration derived from the Interact study but anchored at individual sleeping heart rate (19).

Data from the monitors was downloaded on a PC using the Actiheart software. All files were checked for corrupt data and wear time and non-wear time was checked against logs to see if times fitted according to registered start and ending of wear-period. Heart rate data were preprocessed to eliminate sensor noise using a JAVA program implementing the Bayesian procedure (20) whilst minimising potential diurnal bias caused by non-wear. Non-wear time was determined from the combination of non-physiological heart rate (large Bayesian error) and periods of prolonged inactivity. Branched equation modelling was used to estimate PAEE $(\mathrm{J} / \mathrm{min} / \mathrm{kg})$ from the minute-by-minute measures of accelerometry and heart rate data (16). This was summarised as average daily PAEE $(\mathrm{kJ} / \mathrm{kg} / \mathrm{day})$ and fractions of time spent at the different activity intensity levels. Intensity was defined based on multiples of a standard value of resting metabolic rate $=71 \mathrm{~J} /(1 \mathrm{MET}=3.5 \mathrm{~mL} \mathrm{O} \cdot \mathrm{min} /-1 \cdot \mathrm{kg})$ whilst minimising potential diurnal bias caused by non-wear (standard METs).-1 [ 71 J.min-1·kg-1])). Individuals with less than 24 hours of monitor wear-time were excluded from this study. 
Combined accelerometry and heart rate monitoring has been successfully validated against isotopic assessment of energy expenditure in UK adults (17) and it has been used for investigating external validation of the IPAQ questionnaire (6) and other physical activity questionnaires such as the Recent Physical Activity Questionnaire $(21,22)$ and the Norwegian Women and Cancer Study questionnaire (23).

For the comparison between PAS2 and combined sensor estimates, data from both methods were categorised into intensity levels: Sedentary (0.9-1.5 METs), light physical activity (>1.5-3.0 METs), moderate physical activity (>3.0-6.0 METs), and vigorous physical activity (>6.0 METs).

\section{Statistical analyses}

The distribution of the questionnaire variables was generally non-normally distributed, and data were therefore analysed by non-parametric statistics. We performed Wilcoxon test for equal medians to investigate if median number of hours reported in PAS2 differed significantly from number of median hours measured objectively. Agreement between PAS2 and the objective measurement was investigated using Bland-Altman plots of mean difference and $95 \%$ limits of agreement (LoA) between measurements. Ranking ability of PAS2 was assessed using polychoric correlation coefficients, an approach for calculating rater-associations between ordered-categorical data that are assumed to be latent continuous variables (24). To investigate whether the criterion validity of the PAS2 questionnaire differed depending on subgroup, the analyses were stratified by age, sex, BMI, education level, employment status, self-rated physical activity level and self-rated work-strain. Total PAEE from PAS2 was calculated by multiplying time and intensity for each item and then summing over all items.

Data analysis was performed using SAS version 9.4.

\section{Results}

The study population comprised 330 individuals, 127 men (38.5\%) and 203 women $(61.5 \%)$, with a mean age of 46.7 years. Small differences in the distribution of age, BMI, educational level and PA at work were seen between men and women (Table 2). In table 3, number of hours spent at the four different intensity levels is presented. For the total population $(n=330)$, median hours per day spent in sedentary behaviour including sleep were 15.0 hours per day according to PAS2, and 17.2 hours per day measured by the objective measurement, which correspond to a median difference of 2.2 hours for sedentary behaviour including sleep (Table 3). Participants spent 7.6 hours per day according to PAS2 and 5.9 hours per day according to Acc+HR engaging in light PA, which corresponds to a difference of 1.7 hours. They spent 0.9 hours per day engaging in moderate activity according to PAS2 and 0.7 hours according to Acc+HR. For vigorous activity, participants reported 0.1 hours per day in PAS2 but registered 0.0 hours per day by Acc+HR. In general, time spent in sedentary behaviour was underestimated when measured by PAS2 compared to Acc+HR and time spent on light, moderate, and vigorous activity was overestimated. The difference in time spent at the four intensity levels measured by PAS2 and Acc+HR was most pronounced 
for unemployed persons and least for younger age-groups and participants with a university degree (Table 3).

Bland Altman plots of differences between PAS2 and objective data showed mean bias of -2.3 hours (95\% limits of agreement: -9.04 to 4.34 ) for sedentary behaviour, 1.68 hours (95\% limits of agreement: 8.02 to -4.62 ) for light activity, 0.55 hours (95\% limits of agreement 3.37 to -2.26 ) for moderate activity and 0.12 hours (95\% limits of agreement: 0.57 to 0.33 ) for vigorous activity (fig. 1). For moderate and vigorous activity the plots indicate heteroscedasticity, i.e. poorer agreement between measurements with increasing number of hours spent in moderate or vigorous activity.

Polychoric correlation coefficients are presented in Table 4 for the four levels of physical activity stratified by gender, age group, BMI, educational level, and employment status. Weak correlation coefficients $(\mathrm{PCC}=-0.06$ to $\mathrm{PCC}=0.22$ ) between PAS2 and $\mathrm{Acc}+\mathrm{HR}$ were seen for sedentary behaviour for all subgroups. For light physical activity correlation coefficients were weak for all subgroups ( $\mathrm{PCC}=-0.11$ to $\mathrm{PCC}=0.32$ ). A moderate correlation was found between PAS2 and Acc+HR for moderate activity in the subgroup University Degree $(\mathrm{PCC}=0.42)$ and Obese $(\mathrm{PCC}=0.40)$ but for all other subgroups correlations were weak ( $\mathrm{PCC}=0.10$ to $\mathrm{PCC}=0.34$ ). Correlations between PAS2 and Acc $+\mathrm{HR}$ were moderate for vigorous physical activity ( $\mathrm{r}=0.26$ to $\mathrm{r}=0.66$ ).

Total daily PAEE estimated from Acc+HR was 176.3 (SD \pm 61.5$) \mathrm{kJ}$ per kg per day, and 247.0 ( $\mathrm{SD} \pm 106.3$ ) $\mathrm{kJ}$ per $\mathrm{kg}$ per day when estimated from PAS2 corresponding to an overestimation of total daily PAEE of $28.8 \%$ by PAS 2 compared to Acc+HR.

\section{Discussion}

In the present study the criterion validity of PAS2 was assessed among 330 Danish adults from the Health2008 study using combined accelerometry and HR monitoring as an objective criterion measure. Overall, PAS2 overestimated time spent in light, moderate, and vigorous intensity physical activity and underestimated time spent in sedentary behaviour, including sleep. PAS2 measured physical activity more accurately in men compared to women, in younger age-groups compared to older age-groups, in men and women with a university degree compared to lower educational levels and in those who held a job compared to those not currently working.

This is the first study to assess criterion validity of PAS2. However, the findings in this study are in line with the results of the criterion validity assessments of a comparable physical activity questionnaire, the IPAQ (25). IPAQ and PAS2 have similar measurement properties although PAS2 is shorter (one page) and has more items on sedentary behaviour and light activity compared to IPAQ. These extra items in PAS2 could be one of the reasons for the overall slightly better agreement between PAS2 and Acc+HR compared to the agreement found between IPAQ and objective measures of physical activity $(6,7,9,11)$.

PAS2 overestimated time spent on light, moderate and vigorous intensity activity and underestimated time spent in sedentary behaviour. This overestimation could in part be due to the effect of social desirability, which could cause participants to over-report hours spent 
on physical activity and under-report time spent in sedentary behaviour. However, two studies found that social desirability had little or no effect on how people responded in selfreport instruments for measuring physical activity $(26,27)$, which suggests that social desirability may not explain why PAS2 overestimate the level of physical activity. Another possible explanation for over-reporting time spent in physical activity may be that in the process of recalling a sport or exercise event, the individual may include getting ready for the activity as part of the actual sport event. This would extend the activity time period and thus cause PAS2 to overestimate time spent on physical activity.

The agreement between PAS2 and Acc+HR appeared to be slightly better in men than in women. Women, to a larger extent than men, underestimated time spent in sedentary behaviour and overestimated time spent in light activity, and correlation coefficients were higher for men than for women in light and moderate activity. Similar gender differences were found for IPAQ $(7,9,28,29)$. One reason could be that women perform less moderate and vigorous intensity activity compared to men and time spent on moderate to vigorous intensity activity is generally easier to recall than low-intensity activities (30), which could cause the discrepancy between men and woman.

Other differences in the agreement between PAS2 and Acc+HR were seen for age, educational level and employment status. PAS2 measured time spent in the four activity intensity levels more accurately in participants with a university degree compared to those with shorter education. This is a noteworthy finding and as PAS2 was designed by people with a university degree, the questionnaire may well be better suited to respondents with a high education level.

The criterion validity of PAS2 was found to be different for unemployed persons compared to participants who held a job. PAS2 underestimated time spent at physical activity compared to Acc+HR, which was an unexpected finding, since the opposite tendency was seen for all other subgroups. This indicates that having a job makes it easier to recall and classify the activities of the day. However, a larger study population would be necessary in order to further investigate the findings related to unemployment, as the group of unemployed participants only comprised 17 men and women in the present study.

\subsection{Strengths and Weaknesses of the Study}

Our study has several strengths. The study population comprised 330 Danish adults, which is a relatively large study population compared to similar criterion validation studies ( 31 , 32). The size of the study population enabled us to perform subgroup analyses to investigate whether PAS2 measured PA better for some groups than others. We used the Acc+HR monitor as criterion measure, which has been shown to be valid elsewhere (33) and is therefore a major strength of this study. The physical activity questionnaire was completed prior to the objective measurement, which ensured that reactivity from wearing a device did not influence the completion of PAS2. We are aware that the objective estimate of physical activity refers to a specific week's activity, but since PAS2 refers to a typical day/typical week this should not have a major impact on the comparisons in the present study. 
A litmitation of this study could be systematic errors in the objective measurement of physical activity, which could have occurred due to the use of a group calibration of the heart rate data, as opposed to individual calibration using a dynamic exercise test. However, we did use individual sleeping heart rate and gender as proxy calibrators, which was recently shown to inflate individual-level error by $<20 \%$ for Acc+HR estimates of PAEE, compared to dynamically calibrated models (17). Another limitation is systematic errors in the Acc +HR measurement, which could have occurred due to reactivity. Participants may have changed their physical activity behaviour towards being more active, simply as a result of wearing the monitor, which could potentially have led to altered agreement between PAS2 and Acc+HR. Sleep could be identified in PAS2 but was not singled out in the Acc+HR data, thus not allowing examination of the bias in sedentary behaviour was due to underestimation of sleep or awake sedentary behaviours. However, the variation in response to the item on sleep duration (item 1) was a lot smaller than the variability of answers given to questions measuring time spent in sedentary behaviour, which indicates that the measurement bias in PAS2 is probably due to difficulties with accurate reporting of awake sedentary behaviours, more so than sleep.

\section{Conclusions}

The results of this study indicate that PAS2 underestimates time spent in sedentary behaviour and overestimates time spent in light, moderate and vigorous activity. However, no other validated questionnaire for measuring physical activity has proved better at measuring physical activity among Danish adults. To determine if PAS2 is a valid questionnaire for measuring physical activity in the general Danish population further validity studies are needed, as the results of the present study can only be generalised to healthy Danish adults between 30 and 60 years of age. Cheap and valid measurement methods of physical activity are necessary for improving the quality of physical activity research and thereby improving the health of Danish adults.

\section{Supplementary Material}

Refer to Web version on PubMed Central for supplementary material.

\section{References}

1. Pedersen BK, Saltin B. Evidence for prescribing exercise as therapy in chronic disease. Scand J Med Sci Sports. 2006; 16(Suppl 1):3-63. [PubMed: 16451303]

2. Thorp AA, Owen N, Neuhaus M, Dunstan DW. Sedentary behaviors and subsequent health outcomes in adults a systematic review of longitudinal studies, 1996-2011. Am J Prev Med. 2011; 41(2):207-15. DOI: 10.1016/j.amepre.2011.05.004 [PubMed: 21767729]

3. de Rezende LF, Rodrigues Lopes M, Rey-Lopez JP, Matsudo VK, Luiz Odo C. Sedentary behavior and health outcomes: an overview of systematic reviews. PloS one. 2014; 9(8):e105620. [PubMed: 25144686]

4. Pedisic Z, Bauman A. Accelerometer-based measures in physical activity surveillance: current practices and issues. British journal of sports medicine. 2015; 49(4):219-23. [PubMed: 25370153]

5. Andersen LG, Groenvold M, Jorgensen T, Aadahl M. Construct validity of a revised Physical Activity Scale and testing by cognitive interviewing. Scand J Public Health. 2010; 38(7):707-14. Epub 2010 Sep 7. DOI: 10.1177/1403494810380099 [PubMed: 20823047] 
6. Dahl-Petersen IK, Hansen AW, Bjerregaard P, Jorgensen ME, Brage S. Validity of the international physical activity questionnaire in the arctic. Med Sci Sports Exerc. 2013; 45(4):728-36. DOI: 10.1249/MSS.0b013e31827a6b40 [PubMed: 23190587]

7. Dyrstad SM, Hansen BH, Holme IM, Anderssen SA. Comparison of self-reported versus accelerometer-measured physical activity. Med Sci Sports Exerc. 2014; 46(1):99-106. DOI: 10.1249/MSS.0b013e3182a0595f [PubMed: 23793232]

8. Hansen AW, Dahl-Petersen I, Helge JW, Brage S, Gronbaek M, Flensborg-Madsen T. Validation of an Internet-based long version of the International Physical Activity Questionnaire in Danish adults using combined accelerometry and heart rate monitoring. J Phys Act Health. 2014; 11(3):654-64. Epub 2013 Feb 8. DOI: 10.1123/jpah.2012-0040 [PubMed: 23416716]

9. Nang EE, Gitau Ngunjiri SA, Wu Y, Salim A, Tai ES, Lee J, et al. Validity of the International Physical Activity Questionnaire and the Singapore Prospective Study Program physical activity questionnaire in a multiethnic urban Asian population. BMC Med Res Methodol. 2011; 11:141. (doi):10.1186/471-2288-11-141. [PubMed: 21995825]

10. Tooze JA, Schoeller DA, Subar AF, Kipnis V, Schatzkin A, Troiano RP. Total daily energy expenditure among middle-aged men and women: the OPEN Study. Am J Clin Nutr. 2007; 86(2): 382-7. [PubMed: 17684209]

11. Lee PH, Macfarlane DJ, Lam TH, Stewart SM. Validity of the International Physical Activity Questionnaire Short Form (IPAQ-SF): a systematic review. Int J Behav Nutr Phys Act. 2011; 8:115. (doi):10.1186/479-5868-8-115. [PubMed: 22018588]

12. Aadahl M, Jorgensen T. Validation of a new self-report instrument for measuring physical activity. Med Sci Sports Exerc. 2003; 35(7):1196-202. [PubMed: 12840642]

13. Aadahl M, Kjaer M, Kristensen JH, Mollerup B, Jorgensen T. Self-reported physical activity compared with maximal oxygen uptake in adults. Eur J Cardiovasc Prev Rehabil. 2007; 14(3): 422-8. [PubMed: 17568243]

14. Thuesen BH, Cerqueira C, Aadahl M, Ebstrup JF, Toft U, Thyssen JP, et al. Cohort Profile: the Health2006 cohort, research centre for prevention and health. Int J Epidemiol. 2014; 43(2):56875. Epub 2013 Apr 24. DOI: 10.1093/ije/dyt009 [PubMed: 23615486]

15. Ainsworth BE, Haskell WL, Leon AS, Jacobs DR Jr, Montoye HJ, Sallis JF, et al. Compendium of physical activities: classification of energy costs of human physical activities. Med Sci Sports Exerc. 1993; 25(1):71-80. [PubMed: 8292105]

16. Brage S, Brage N, Franks PW, Ekelund U, Wong MY, Andersen LB, et al. Branched equation modeling of simultaneous accelerometry and heart rate monitoring improves estimate of directly measured physical activity energy expenditure. 2004; 96(1):343-51. 1985). Epub 2003 Sep 12.

17. Brage S, Westgate K, Franks PW, Stegle O, Wright A, Ekelund U, et al. Estimation of Free-Living Energy Expenditure by Heart Rate and Movement Sensing: A Doubly-Labelled Water Study. PloS one. 2015; 10(9):e0137206. [PubMed: 26349056]

18. Camtech. The Actiheart Guide to Getting Started. 2010. Contract No.: 30072

19. Peters T, Brage S, Westgate K, Franks PW, Gradmark A, Tormo Diaz MJ, et al. Validity of a short questionnaire to assess physical activity in 10 European countries. Eur J Epidemiol. 2012; 27(1): 15-25. Epub 2011 Nov 17. DOI: 10.1007/s10654-011-9625-y [PubMed: 22089423]

20. Stegle O, Fallert SV, MacKay DJ, Brage S. Gaussian process robust regression for noisy heart rate data. IEEE transactions on bio-medical engineering. 2008; 55(9):2143-51. [PubMed: 18713683]

21. Besson H, Brage S, Jakes RW, Ekelund U, Wareham NJ. Estimating physical activity energy expenditure, sedentary time, and physical activity intensity by self-report in adults. The American journal of clinical nutrition. 2010; 91(1):106-14. [PubMed: 19889820]

22. Golubic R, May AM, Benjaminsen Borch K, Overvad K, Charles MA, Diaz MJ, et al. Validity of electronically administered Recent Physical Activity Questionnaire (RPAQ) in ten European countries. PloS one. 2014; 9(3):e92829. [PubMed: 24667343]

23. Borch KB, Ekelund U, Brage S, Lund E. Criterion validity of a 10-category scale for ranking physical activity in Norwegian women. The international journal of behavioral nutrition and physical activity. 2012; 9:2. [PubMed: 22260340]

24. Ekström J. On the Relation Between the Polychoric Correlation Coefficient and Spearman's Rank Correlation Coefficien. Department of Statistics Papers. 2011; 15 
25. Craig CL, Marshall AL, Sjostrom M, Bauman AE, Booth ML, Ainsworth BE, et al. International physical activity questionnaire: 12-country reliability and validity. Med Sci Sports Exerc. 2003; 35(8):1381-95. [PubMed: 12900694]

26. Crutzen R, Goritz AS. Does social desirability compromise self-reports of physical activity in webbased research? Int J Behav Nutr Phys Act. 2011; 8:31.doi: 10.1186/479-5868-8-31 [PubMed: 21492435]

27. Motl RW, McAuley E, DiStefano C. Is social desirability associated with self-reported physical activity? Prev Med. 2005; 40(6):735-9. [PubMed: 15850873]

28. Lee PH, Yu YY, McDowell I, Leung GM, Lam TH, Stewart SM. Performance of the international physical activity questionnaire (short form) in subgroups of the Hong Kong chinese population. Int J Behav Nutr Phys Act. 2011; 8:81.doi: 10.1186/479-5868-8-81 [PubMed: 21801461]

29. Wolin KY, Heil DP, Askew S, Matthews CE, Bennett GG. Validation of the International Physical Activity Questionnaire-Short among Blacks. J Phys Act Health. 2008; 5(5):746-60. [PubMed: 18820348]

30. Matthews CE, Ainsworth BE, Thompson RW, Bassett DR Jr. Sources of variance in daily physical activity levels as measured by an accelerometer. Medicine and science in sports and exercise. 2002; 34(8):1376-81. [PubMed: 12165695]

31. Macfarlane DJ, Lee CC, Ho EY, Chan KL, Chan DT. Reliability and validity of the Chinese version of IPAQ (short, last 7 days). J Sci Med Sport. 2007; 10(1):45-51. Epub 2006 Jun 30. [PubMed: 16807105]

32. Mader U, Martin BW, Schutz Y, Marti B. Validity of four short physical activity questionnaires in middle-aged persons. Med Sci Sports Exerc. 2006; 38(7):1255-66. [PubMed: 16826022]

33. Crouter SE, Churilla JR, Bassett DR Jr. Accuracy of the Actiheart for the assessment of energy expenditure in adults. Eur J Clin Nutr. 2008; 62(6):704-11. Epub 2007 Apr 18. [PubMed: 17440515] 

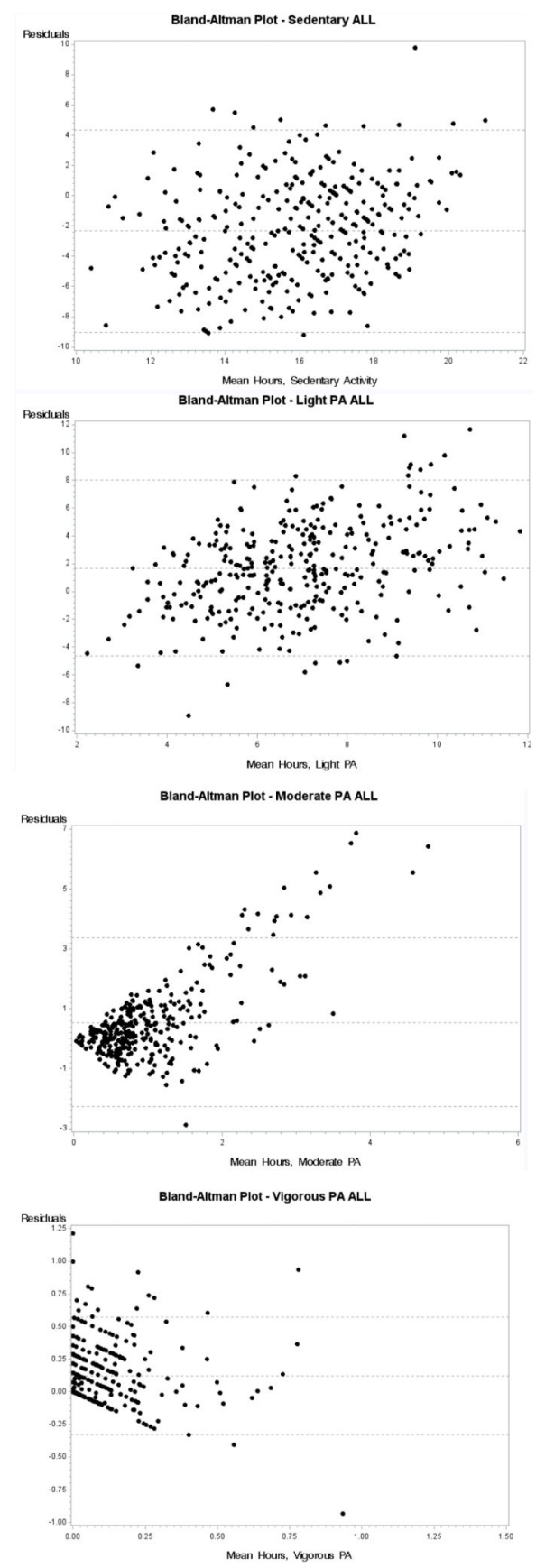

Figure 1. Bland-Altman plots of the agreement between self-reported PA (PAS2) and objectively measured PA $(\mathrm{Acc}+\mathrm{HR})$ for the total population $(n=330)$

X-axis: mean hours of Acc+HR. Y-axis: absolute difference between PAS2 and Acc+HR.

The line in the middle represent mean difference between the two measurement methods and the lower and upper line represent $95 \%$ limits of agreement. 
Table 1

Overview of the items of PAS2 and specific questions related to each item.

\begin{tabular}{|c|c|c|}
\hline $\begin{array}{l}\text { Item } \\
\text { (number of } \\
\text { question) }\end{array}$ & Topic & Question \\
\hline Item 1 & Sleep & $\begin{array}{l}\text { How many hours and minutes do you sleep on an average weekday? (include rest or naps } \\
\text { during the day) }\end{array}$ \\
\hline Item 2 & Sedentary behaviour, work & $\begin{array}{l}\text { In your work/studies, how many hours and minutes per day do you engage in sedentary } \\
\text { work? }\end{array}$ \\
\hline Item 2 & Standing/walking at work & $\begin{array}{l}\text { In your work/studies, how many hours and minutes per day do you engage in standing or } \\
\text { walking work? }\end{array}$ \\
\hline Item 2 & Strenuous activity at work & $\begin{array}{l}\text { In your work/studies, how many hours and minutes per day do you engage in heavy } \\
\text { physical work? (for instance heavy lifting or climbing stairs) }\end{array}$ \\
\hline Item 3 & Cycling/walking as transportation & $\begin{array}{l}\text { How many hours and minutes per day do you ride a bicycle or walk for transportation to } \\
\text { and from work? }\end{array}$ \\
\hline Item 4 & Sedentary behaviour, leisure & $\begin{array}{l}\text { In your leisure time, how many hours and minutes per day do you spend with watching } \\
\mathrm{TV} \text {, sitting quietly, reading, and listening to music or the like? }\end{array}$ \\
\hline Item 5 & Light PA, leisure & $\begin{array}{l}\text { In your leisure time, how many hours and minutes per week do you engage in light } \\
\text { physical activity such as walking, light cleaning, raking lawn, or light exercise such as } \\
\text { yoga, bowling or similar activities? }\end{array}$ \\
\hline Item 6 & Moderate PA, leisure & $\begin{array}{l}\text { In your leisure time, how many hours and minutes per week do you engage in gardening, } \\
\text { carrying loads upstairs or moderately strenuous sport such as gymnastics, swimming, } \\
\text { bicycling, strength conditioning or similar activities? (do not include transportation to and } \\
\text { from work) }\end{array}$ \\
\hline Item 7 & Vigorous PA, leisure & $\begin{array}{l}\text { In your leisure time, how many hours and minutes per week do you engage in strenuous } \\
\text { sport and conditioning exercise such as running, jogging, soccer, tennis, aerobics or } \\
\text { similar activities? (do not include transportation to and from work) }\end{array}$ \\
\hline
\end{tabular}

Translation of PAS2 questions taken from Andersen et al. (19). A pictogram exemplifying the level of activity is positioned to the left of every item. 


\section{Table 2}

\section{Characteristics of study participants}

\begin{tabular}{lrrrrrr}
\hline Variable & \multicolumn{1}{c}{ All } & \multicolumn{2}{c}{ Men } & \multicolumn{2}{c}{ Women } \\
\hline Gender & 330 & $(100)$ & 127 & $(38.5)$ & 203 & $(61.5)$ \\
Age, years (Mean \pm SD) & 46.7 & \pm 8.5 & 46.4 & \pm 9.1 & 46.9 & \pm 8.1 \\
Age groups & & & & & & \\
$\quad 30-39$ & 86 & $(26.1)$ & 42 & $(33.0)$ & 44 & $(21.7)$ \\
$40-49$ & 112 & $(33.9)$ & 33 & $(26.0)$ & 79 & $(38.9)$ \\
50-60 & 132 & $(40.0)$ & 52 & $(40.9)$ & 80 & $(39.4)$ \\
BMI, Kg*m-2 (Mean \pm SD) & 25.6 & \pm 4.4 & 26.8 & \pm 3.8 & 24.9 & \pm 4.5 \\
$\quad$ Underweight or normal (BMI $<25)$ & 167 & $(50.6)$ & 44 & $(34.7)$ & 123 & $(60.6)$ \\
$\quad$ Overweight (BMI =25 - 29.99) & 118 & $(35.8)$ & 61 & $(48.0)$ & 57 & $(28.1)$ \\
$\quad$ Obese (BMI $\geq 30)$ & 45 & $(13.6)$ & 22 & $(17.3)$ & 23 & $(11.3)$ \\
Educational level & & & & & & \\
$\quad$ Short (less than a year) & 38 & $(11.5)$ & 20 & $(15.8)$ & 18 & $(8.9)$ \\
$\quad$ Skilled education & 91 & $(27.6)$ & 44 & $(34.7)$ & 47 & $(23.1)$ \\
$\quad$ Short higher education & 73 & $(22.1)$ & 15 & $(11.8)$ & 58 & $(28.6)$ \\
$\quad$ Middle-long higher education & 77 & $(23.3)$ & 21 & $(16.5)$ & 56 & $(27.6)$ \\
$\quad$ University degree & 45 & $(13.6)$ & 26 & $(20.5)$ & 19 & $(9.4)$ \\
$\quad$ Other & 6 & $(1.8)$ & 1 & $(0.8)$ & 5 & $(2.5)$ \\
Job status & & & & & & \\
$\quad$ Employed & 313 & $(94.9)$ & 121 & $(95.3)$ & 192 & $(94.6)$ \\
$\quad$ Former employed & 17 & $(5.2)$ & 6 & $(4.7)$ & 11 & $(5.4)$ \\
$\quad$ Never employed & - & & - & & - & \\
\hline
\end{tabular}

This table is presented with mean \pm SD for continuous variables (age and BMI) and $\mathrm{n}(\%)$ for categorical variables (remaining variables). 
Table 3

Hours spent at different MET-levels for PAS2 and Acc+HR

\begin{tabular}{|c|c|c|c|c|c|c|c|c|}
\hline & \multicolumn{2}{|c|}{$\begin{array}{l}\text { Sedentary time } \\
(\leq 1.5 \text { MET })\end{array}$} & \multicolumn{2}{|c|}{$\begin{array}{l}\text { Light PA } \\
\text { (1.5-3.0 MET) }\end{array}$} & \multicolumn{2}{|c|}{$\begin{array}{l}\text { Moderate PA } \\
\text { (3.0-6.0 MET) }\end{array}$} & \multicolumn{2}{|c|}{$\begin{array}{l}\text { Vigorous PA } \\
\text { (> } 6 \text { MET) }\end{array}$} \\
\hline & Hours & I.Q. range & Hours & I.Q. range & Hours & I.Q. range & Hours & I.Q. range \\
\hline \multicolumn{9}{|c|}{ ALL $(N=330)$} \\
\hline PAS2 & 15.0 & $12.5-17.0^{*}$ & 7.6 & $5.9-9.7^{*}$ & 0.9 & $0.5-1.6^{*}$ & 0.1 & $0.0-0.3^{*}$ \\
\hline $\mathrm{Acc}+\mathrm{HR}$ & 17.2 & $15.4-18.7$ & 5.9 & $4.7-7.5$ & 0.7 & $0.4-1.0$ & 0.0 & $0.0-0.1$ \\
\hline \multicolumn{9}{|c|}{$\operatorname{Men}(N=127)$} \\
\hline PAS2 & 14.5 & $12.0-17.0^{*}$ & 7.4 & $5.3-9.6^{*}$ & 1.0 & $0.5-1.8^{*}$ & 0.1 & $0.0-0.4^{*}$ \\
\hline $\mathrm{Acc}+\mathrm{HR}$ & 16.8 & $14.6-18.5$ & 6.3 & $4.8-8.1$ & 0.7 & $0.4-1.1$ & 0.1 & $0.0-0.2$ \\
\hline \multicolumn{9}{|c|}{ Women $(\mathrm{N}=\mathbf{2 0 3})$} \\
\hline PAS2 & 15.0 & $12.5-17.0^{*}$ & 7.6 & $6.1-9.7^{*}$ & 0.9 & $0.5-1.4^{*}$ & 0.1 & $0.0-0.3^{*}$ \\
\hline $\mathrm{Acc}+\mathrm{HR}$ & 17.5 & $15.9-18.8$ & 5.8 & $4.7-7.1$ & 0.6 & $0.3-0.9$ & 0.0 & $0.0-0.1$ \\
\hline \multicolumn{9}{|l|}{ Age Group } \\
\hline \multicolumn{9}{|l|}{$30-39(\mathrm{~N}=86)$} \\
\hline PAS2 & 14.9 & $11.5-17.0 *$ & 7.8 & $6.5-10.9^{*}$ & 0.9 & $0.4-1.4$ & 0.1 & $0.0-0.3^{*}$ \\
\hline $\mathrm{Acc}+\mathrm{HR}$ & 15.1 & $14.3-17.2$ & 7.4 & $5.8-8.5$ & 0.8 & $0.6-1.3$ & 0.1 & $0.0-0.2$ \\
\hline \multicolumn{9}{|c|}{$40-49(N=112)$} \\
\hline PAS2 & 15.0 & $12.5-16.8^{*}$ & 7.5 & $6.0-9.7^{*}$ & 0.8 & $0.4-1.5^{*}$ & 0.2 & $0.0-0.4^{*}$ \\
\hline $\mathrm{Acc}+\mathrm{HR}$ & 17.6 & $16.1-18.9$ & 5.8 & $4.6-7.1$ & 0.6 & $0.3-0.9$ & 0.1 & $0.0-0.1$ \\
\hline \multicolumn{9}{|c|}{$50-60(\mathrm{~N}=132)$} \\
\hline PAS2 & 15.0 & $13.0-17.0 *$ & 7.3 & $5.4-9.1 *$ & 0.9 & $0.6-1.7^{*}$ & 0.0 & $0.0-0.3^{*}$ \\
\hline $\mathrm{Acc}+\mathrm{HR}$ & 18.0 & $16.5-19.0$ & 5.3 & $4.4-6.7$ & 0.6 & $0.4-0.9$ & 0.0 & $0.0-0.1$ \\
\hline \multicolumn{9}{|l|}{ BMI Group } \\
\hline \multicolumn{9}{|c|}{ BMI $<25(N=167)$} \\
\hline PAS2 & 15.0 & $12.5-17.0^{*}$ & 7.8 & $6.1-9.7$ * & 0.9 & $0.5-1.4^{*}$ & 0.1 & $0.0-0.3^{*}$ \\
\hline $\mathrm{Acc}+\mathrm{HR}$ & 17.2 & $15.6-18.7$ & 5.9 & $4.7-7.2$ & 0.7 & $0.4-1.0$ & 0.1 & $0.0-0.2$ \\
\hline \multicolumn{9}{|c|}{ BMI 25-30 (N=118) } \\
\hline PAS2 & 15.0 & $12.5-17.0^{*}$ & 7.3 & $5.1-9.6^{*}$ & 0.9 & $0.5-1.8^{*}$ & 0.1 & $0.0-0.4^{*}$ \\
\hline $\mathrm{Acc}+\mathrm{HR}$ & 17.0 & $15.3-18.6$ & 6.1 & $4.7-7.5$ & 0.6 & $0.3-1.0$ & 0.0 & $0.0-0.1$ \\
\hline \multicolumn{9}{|c|}{ BMI $\geq 30(N=45)$} \\
\hline PAS2 & 15.5 & $12.5-17.0 *$ & 7.1 & $6.5-9.5^{*}$ & 1.0 & $0.5-1.4$ & 0.0 & $0.0-0.4^{*}$ \\
\hline $\mathrm{Acc}+\mathrm{HR}$ & 17.5 & $14.6-18.6$ & 5.8 & $4.8-8.3$ & 0.7 & $0.4-1.0$ & 0.0 & $0.0-0.1$ \\
\hline \multicolumn{9}{|c|}{ Educational level } \\
\hline \multicolumn{9}{|c|}{ University Degree $(\mathrm{N}=45)$} \\
\hline PAS2 & 16.5 & $14.0-17.5$ & 6.6 & $5.4-8.5$ & 0.7 & $0.5-1.1$ & 0.1 & $0.0-0.3$ \\
\hline Acc+HR & 17.0 & $15.0-18.8$ & 6.0 & $4.8-7.5$ & 0.7 & $0.4-0.9$ & 0.1 & $0.0-0.2$ \\
\hline \multicolumn{9}{|c|}{ Other Education ( $\mathbf{N}=\mathbf{2 8 5}$ ) } \\
\hline PAS2 & 14.5 & $12.3-17.0^{*}$ & 7.7 & $6.0-9.8^{*}$ & 0.9 & $0.5-1.6^{*}$ & 0.1 & $0.0-0.4^{*}$ \\
\hline
\end{tabular}




\begin{tabular}{|c|c|c|c|c|c|c|c|c|}
\hline & \multicolumn{2}{|c|}{$\begin{array}{l}\text { Sedentary time } \\
(\leq 1.5 \text { MET })\end{array}$} & \multicolumn{2}{|c|}{$\begin{array}{l}\text { Light PA } \\
\text { (1.5-3.0 MET) }\end{array}$} & \multicolumn{2}{|c|}{$\begin{array}{l}\text { Moderate PA } \\
\text { (3.0-6.0 MET) }\end{array}$} & \multicolumn{2}{|c|}{$\begin{array}{l}\text { Vigorous PA } \\
\text { (> } 6 \text { MET) }\end{array}$} \\
\hline & Hours & I.Q. range & Hours & I.Q. range & Hours & I.Q. range & Hours & I.Q. range \\
\hline $\mathrm{Acc}+\mathrm{HR}$ & 17.2 & $15.5-18.6$ & 5.9 & $4.7-7.5$ & 0.7 & $0.4-1.0$ & 0.0 & $0.0-0.1$ \\
\hline \multicolumn{9}{|c|}{ Employment status } \\
\hline \multicolumn{9}{|c|}{ Employed (N=313) } \\
\hline PAS2 & 15.0 & $12.5-17.0^{*}$ & 7.6 & $5.9-9.6^{*}$ & 0.9 & $0.5-1.6^{*}$ & 0.1 & $0.0-0.4^{*}$ \\
\hline $\mathrm{Acc}+\mathrm{HR}$ & 17.3 & $15.5-18.7$ & 5.9 & $4.7-7.5$ & 0.7 & $0.4-1.0$ & 0.0 & $0.0-0.1$ \\
\hline \multicolumn{9}{|c|}{ Unemployed ( $N=17)$} \\
\hline PAS2 & 13.0 & $11.0-17.5$ & 10.1 & $6.0-11.7$ & 0.4 & $0.0-0.7$ & 0.0 & $0.0-0.1$ \\
\hline $\mathrm{Acc}+\mathrm{HR}$ & 16.5 & 14.4-18.1 & 6.6 & $4.9-8.6$ & 0.8 & $0.4-1.1$ & 0.0 & $0.0-0.0$ \\
\hline
\end{tabular}


Table 4

Polychoric correlation coefficients (PCC) between self-reported PA (PAS2) and objectively measured PA (Acc+HR)

\begin{tabular}{|c|c|c|c|c|c|c|c|c|}
\hline & \multicolumn{2}{|c|}{$\begin{array}{l}\text { Sedentary } \\
(<1.5 \mathrm{MET})\end{array}$} & \multicolumn{2}{|c|}{$\begin{array}{l}\text { Light PA } \\
\text { (1.5 - } 3 \text { MET) }\end{array}$} & \multicolumn{2}{|c|}{$\begin{array}{l}\text { Moderate PA } \\
\text { (3 - } 6 \text { MET) }\end{array}$} & \multicolumn{2}{|c|}{$\begin{array}{l}\text { Vigorous PA } \\
\text { (> } 6 \mathrm{MET})\end{array}$} \\
\hline & PCC & p-value & PCC & p-value & PCC & p-value & PCC & p-value \\
\hline All & 0.197 & 0.053 & 0.180 & 0.053 & 0.204 & 0.053 & 0.535 & 0.044 \\
\hline \multicolumn{9}{|l|}{ Gender } \\
\hline Men & 0.222 & 0.085 & 0.207 & 0.085 & 0.338 & 0.079 & 0.431 & 0.078 \\
\hline Women & 0.195 & 0.068 & 0.182 & 0.068 & 0.103 & 0.070 & 0.593 & 0.053 \\
\hline \multicolumn{9}{|l|}{ Age Group } \\
\hline $30-39$ & 0.341 & 0.096 & 0.320 & 0.098 & 0.325 & 0.097 & 0.391 & 0.098 \\
\hline $40-49$ & 0.143 & 0.093 & 0.104 & 0.094 & 0.209 & 0.091 & 0.578 & 0.069 \\
\hline $50-60$ & 0.133 & 0.086 & 0.069 & 0.089 & 0.192 & 0.084 & 0.529 & 0.076 \\
\hline \multicolumn{9}{|l|}{ BMI } \\
\hline Normal Weight & 0.189 & 0.075 & 0.208 & 0.074 & 0.142 & 0.076 & 0,568 & 0.058 \\
\hline Overweight & 0.218 & 0.088 & 0.190 & 0.089 & 0.206 & 0.089 & 0.487 & 0.080 \\
\hline Obese & 0.152 & 0.147 & 0.136 & 0.148 & 0.395 & 0.127 & 0.660 & 0.105 \\
\hline \multicolumn{9}{|l|}{ Educational level } \\
\hline University Degree & 0.180 & 0.146 & 0.190 & 0.145 & 0.416 & 0.125 & 0.590 & 0.106 \\
\hline Other Education & 0.209 & 0.057 & 0.180 & 0.058 & 0.177 & 0.058 & 0.544 & 0.047 \\
\hline \multicolumn{9}{|l|}{ Employment status } \\
\hline Employed & 0.219 & 0.054 & 0.202 & 0.054 & 0.210 & 0.054 & 0.259 & 0.046 \\
\hline Unemployed & -0.057 & 0.247 & -0.112 & 0.245 & 0.323 & 0.232 & 0.481 & 0.257 \\
\hline
\end{tabular}

PCC $=$ Polychoric Correlation 